\title{
DEVELOPMENT OF A NOVEL HEADSPACE SORPTIVE EXTRACTION \\ METHOD TO STUDY THE AGING OF VOLATILE COMPOUNDS IN SPENT \\ HANDGUN CARTRIDGES
}

Mars 2014

\author{
M. Gallidabino ${ }^{\mathrm{a}, *}$, F. S. Romolo ${ }^{\mathrm{a}, \mathrm{b}}$, K. Bylenga ${ }^{\mathrm{c}}$, C. Weyermann ${ }^{\mathrm{a}}$ \\ a Université de Lausanne, École des Sciences Criminelles, Institut de Police Scientifique, Bâtiment \\ Batochime, 1015 Lausanne-Dorigny, Switzerland \\ b Sapienza Università di Roma, Department SAIMLAL, Viale Regina Elena 336, 00161 Rome, Italy \\ ${ }^{\mathrm{c}}$ King's College London, School of Biomedical and Health Sciences, Department of Forensic Sci- \\ ence \& Drug Monitoring, 150 Stamford Street, London SE1 9NH, United Kingdom
}

\footnotetext{
Abstract

Estimating the time since the last discharge of firearms and/or spent cartridges may be a useful piece of information in forensic firearm-related cases. The current approach consists of studying the diffusion of selected volatile organic compounds (such as naphthalene) released during the shooting using solid phase micro-extraction (SPME). However, this technique works poorly on handgun cartridges because the extracted quantities quickly fall below the limit of detection.

In order to find more effective solutions and further investigate the aging of organic gunshot residue after the discharge of handgun cartridges, an extensive study was carried out in this work using a novel approach based on high capacity headspace sorptive extraction (HSSE). By adopting this technique, for the first time 51 gunshot residue (GSR) volatile organic compounds could be simultaneously detected from fired handgun cartridge cases. Application to aged specimens showed that many of those compounds presented significant and complementary aging profiles. Compound-tocompound ratios were also tested and proved to be beneficial both in reducing the variability of the aging curves and in enlarging the time window useful in a forensic casework perspective. The ob-
} 
tained results were thus particularly promising for the development of a new complete forensic dating methodology.

* Corresponding author (e-mail: matteo.gallidabino@unil.ch; phone: +41 2169246 39; fax: +41 2169246 05) 


\section{Introduction}

Estimating the time since the last discharge of firearms and/or spent cartridges may be a useful piece of information in firearm-related cases ${ }^{1,2}$. In fact, the validity of the collected evidence may sometimes be contested by stating that a seized gun was not recently fired, or alternatively, that a questioned empty cartridge found at the crime scene had been fired long before the commission of the crime. In such cases, estimating the time since discharge would help in reaching a conclusion. Several approaches were previously suggested to address this issue, and most exploited the measure of changes in the gunshot residue (GSR) after the discharge ${ }^{3-8}$. The term "GSR" refers to the different materials released as a secondary result during the discharge of a firearm ${ }^{9,10}$. These mainly include unburned and partially burned flakes of smokeless powder ${ }^{11,12}$, condensed metallic particles formed after the explosion of the primer ${ }^{13,14}$, and many explosion products and by-products coming from the deflagration of the propellant and the primer mixture ${ }^{15,16}$. GSR is thus a complex and heterogeneous mixture composed of both organic and inorganic species, possibly undergoing some aging mechanisms after the shot. In this regard, many organic GSR substances have significant vapour pressures and are thus particularly suitable for estimating the time since the last discharge ${ }^{15}$. Amongst them, we can find smokeless powder components such as nitroglycerin, diphenylamine, ethylcentralite, dibutylphthalate and 2-ethyl-1-hexanol ${ }^{17,18}$. Many organic reaction by-products were also identified, and these are mainly derivatives of benzene (e.g., benzonitrile and tolunitrile) and polycyclic aromatic hydrocarbons (PAHs) (e.g., naphthalene, acenapthene and pyrene) $)^{19}$.

Solid phase micro-extraction (SPME) proved to be a promising solution for sampling such compounds in a GSR dating method ${ }^{15}$. SPME is a solvent-free extraction technique based on the partition equilibrium of analytes between a matrix and a small amount of sorbent phase coated on a fused silica fibre ${ }^{20}$. GSR dating approaches using this technique were generally based on measuring the evolution of selected target compounds by repeated sampling from the inner space of the questioned objects (such as barrels or spent cartridges). In this way, a partial aging curve was constructed and could be compared to a complete reference profile to infer the time since discharge ${ }^{15}$. Naphthalene and some unidentified decomposition products of nitrocellulose were suggested as target compounds ${ }^{15}$. Particular attention was devoted to the choice of the optimal coating material. Polydimethylsiloxane (PDMS), polyacrylate (PA), and mixed carboxen/polydimethylsiloxane (CAR/PDMS) were tested, and it was found that PA offered better sensitivity towards the selected target analytes ${ }^{16}$. Gas chromatography (GC) was generally recommended for analysis, coupled to a thermal energy analyser (TEA) for the nitrocellulose decomposition products ${ }^{15,21}$, or to a flame ionization detector (FID) ${ }^{15}$ or mass spectrometer (MS) ${ }^{22}$ for naphthalene. 
SPME proved to be promising for dating the last discharge of shotguns, rifles, and related shells/cartridges ${ }^{15,21,23}$. However, when the method was applied to handguns and their cartridges, repeatability issues ${ }^{16}$ and aging curves quickly falling below the limits of detection for the considered target compounds ${ }^{16,23,24}$ were observed. No comprehensive studies were carried out using more effective extraction techniques and/or targeting less volatile compounds than naphthalene and nitrocellulose decomposition products. Therefore, the possibility of dating the discharge of handgun firearms and cartridges by sampling their GSR volatile organic compounds is still largely unexplored.

The purpose of this research was to study the aging of several GSR volatile organic compounds using a novel high capacity extraction technique, the so-called headspace sorptive extraction (HSSE). While HSSE and SPME are based on the same extraction principles, the extracting support of the former is a magnetic stir bar coated with a larger volume of sorbent phase in comparison to SPME fibres (up to $110 \mu \mathrm{L}$ vs. a maximum of $0.5 \mu \mathrm{L}$, respectively) ${ }^{25}$. This feature generally guarantees better recovery yields with benefits for sensitivity and repeatability ${ }^{25,26}$, making HSSE particularly promising for studying more comprehensively the GSR aging processes in spent cartridges. Thermal desorption coupled to gas chromatography/mass spectrometry (TD/GC/MS) was used to recover and analyse the volatile compounds absorbed by HSSE stir bars. A data post-treatment approach involving compound-to-compound ratios was also applied in order to reduce variability of the aging curves and increase the measurable time ranges. These implementations resulted in an innovative analytical procedure expected to bring a significant contribution in a key forensic field.

\section{Experimental section}

\section{$\underline{\text { Reference substances and solvents }}$}

Pure standards of 55 compounds previously identified in GSRs were purchased from various chemical companies (see details in Supporting Information, Table S-1): (\#1) benzene, (\#2) toluene, (\#3) ethylbenzene, (\#4a) p-xylene, (\#4b) m-xylene, (\#5) styrene, (\#6) o-xylene, (\#7) benzaldehyde, (\#7) benzonitrile, (\#9) 2-ethyl-1-hexanol, (\#10) indene, (\#11) acetophenone, (\#12) o-tolunitrile, (\#13) mtolunitrile, (\#14) p-tolunitrile, (\#15) benzyl nitrile, (\#16) naphthalene, (\#17) benzo[b]thiophene, (\#18) benzothiazole, (\#19) quinoline, (\#20) isoquinoline, (\#21a) 1,4-dicyanobenzene, (\#21b) 1,3dicyanobenzene, (\#22) indole, (\#23) 2-mehtylnaphthalene, (\#24) 1-methylnaphthalene, (\#25) 1,2dicyanobenzene, (\#26) biphenyl, (\#27) 2-ethylnaphthalene, (\#28) 2,6-dimehtylnaphthalene, (\#29) 1,4-dimethylnaphthalene, (\#30) acenaphthylene, (\#31) biphenylene, (\#32) acenaphthene, (\#33) 4methylbiphenyl, (\#34) 1-naphthalenecarbonitrile, (\#35) 2-naphthalenecarbonitrile, (\#36) fluorene, 
(\#37) diphenylamine, (\#38) benzophenone, (\#39) phenanthrene, (\#40) anthracene, (\#41) carbazole, (\#42) ethylcentralite, (\#43) dibutylphthalate, (\#44) 2-nitrodiphenylamine, (\#45) 1-methyl-3,3diphenylurea, (\#46) fluoranthene, (\#47) pyrene, (\#48) 4-nitrodiphenylamine, (\#49) 2,4dinitrodiphenylamine, (\#50) chrysene, (\#51) benzo[a]pyrene, (\#52) nitroglycerin, (\#53) Nnitrosodiphenylamine (compounds were numbered according to their elution order, while co-eluting and undistinguishable compounds were annotated with letters). For each substance, a working standard solution was prepared at a concentration of $1 \mathrm{mg} \cdot \mathrm{mL}^{-1}$ in methanol (puriss. grade) purchased from Sigma/Aldrich (Buchs, Switzerland), except for anthracene, chrysene and benzo[a]pyrene which were dissolved in chloroform (purum grade) also purchased from Sigma/Aldrich. Nitroglycerin was already dissolved in a mixture of ethanol/methanol (97:3).

\section{Ammunition and test shootings}

Nine types of ammunition were purchased in 2011 from various sellers in Switzerland: five .45 ACP cartridges (produced by Geco, PMC, UMC, Sellier \& Bellot and Magtech) and four .357 Magnum cartridges (produced by Geco, Sellier \& Bellot, Samson and Magtech). All ammunition contained double-base smokeless powders (i.e., they contained both nitrocellulose and nitroglycerin as main explosives) except for the .45 ACP Magtech cartridges which contained a single-base smokeless powder (i.e., it contained only nitrocellulose).

The test shootings were carried out using a Colt 1911 semi-automatic pistol (.45 ACP) and a Colt Python revolver (.357 Magnum). Development of the method was carried out using all types of ammunition, while the aging profiles were solely acquired on the Geco and Magtech .45 ACP cartridges. In fact, semi-automatic pistol spent cartridges are actually more often found on crime scene given that they are ejected from the firearm after the discharge, contrary to revolver cartridges which stays in the revolving cylinder. Before each shooting event, firearms were carefully cleaned with dry cleaning patches. Five consecutive shots with a generic type of ammunition were additionally performed to remove any excess oils and lubricants. Then, test cartridges were fired by singly loading them in the magazine/barrel.

Spent cartridges analysed at time $\mathrm{t}=0 \mathrm{~h}$ were immediately recovered after the discharge and put in $20 \mathrm{~mL}$ HSSE-dedicated crimp glass vials (Gerstel, Sursee, Switzerland). $20 \mathrm{~mL}$ crimp vials were found to be a good solution because their large opening (i.e., $13 \mathrm{~mm}$ ) fits well with most handgun calibres. Vials were closed with $20 \mathrm{~mm}$ crimp caps equipped with $3.0 \mathrm{~mm}$ PTFE/silicon septa (Gerstel). Spent cartridges analysed at time $\mathrm{t}>0 \mathrm{~h}$ were aged with openings facing upward in an air 
conditioned laboratory kept at a temperature of about $20^{\circ} \mathrm{C}$. For each type of test, cartridges were fired in three replicates.

\section{$\underline{\text { HSSE extraction of spent cartridges }}$}

HSSE stir bars are commercialized under the name of "Twister ${ }^{\complement}$ " by Gerstel. The largest available PDMS-coated HSSE stir bars $(2 \mathrm{~cm}$ length per $1 \mathrm{~mm}$ coating thickness, corresponding to a PDMS volume of $110 \mu \mathrm{L}$ ) were purchased. These were chosen to provide the maximum extraction capability. Stir bars were always thermo-conditioned before use. To do this, they were put in ad-hoc glass desorption tubes (Gerstel) and placed in a Gerstel TC tube conditioner. The conditioning procedure suggested by the producer ( $30 \mathrm{~min}$ at laboratory temperature, followed by $90 \mathrm{~min}$ at $300{ }^{\circ} \mathrm{C}$ and about $60 \mathrm{~min}$ for cooling down) was used.

For the extraction, one stir bar was suspended with the aid of a special glass insert (Gerstel) in the headspace of each vial containing one fired cartridge. Cartridges were extracted in a laboratory oven at $80{ }^{\circ} \mathrm{C}$ for $72 \mathrm{~h}$. Before analysis, vials were reopened. Then, the stir bars were retrieved and placed in reconditioned desorption tubes. Finally, the tubes were capped with special transportation adapters (Gerstel) and placed on the GC tray for TD/GC/MS analysis.

\section{$\underline{\mathrm{TD} / \mathrm{GC} / \mathrm{MS} \text { analysis of stir bars }}$}

Stir bars were thermally desorbed using a Gerstel TDU thermal desorption unit connected to a Gerstel CIS-4 programmed temperature vaporizing injector. These devices were mounted on an Agilent 7890A gas chromatograph coupled to an Agilent 5975C mass selective detector (Agilent Technologies, Basel, Switzerland). The system was also equipped with a Gerstel MPS multi-purpose sampler which was used to automatically load tubes containing stir bars into the TDU.

Desorption mode was splitless, desorption flow $40 \mathrm{~mL} \cdot \mathrm{min}^{-1}$, and desorption pressure 9.07 psi. The desorption ramp was programmed as follows: $20{ }^{\circ} \mathrm{C}$ for $0.5 \mathrm{~min}$, ramped to $250{ }^{\circ} \mathrm{C}$ at $60{ }^{\circ} \mathrm{C} \cdot \mathrm{min}^{-1}$ and held at this temperature for $10 \mathrm{~min}$ (total desorption time of $14.3 \mathrm{~min}$ ). The transfer line temperature between TDU and CIS- 4 was $280{ }^{\circ} \mathrm{C}$. Liners for CIS-4 were obtained from Gerstel and packed with quartz-wool. The cryo-focusing temperature was $-80{ }^{\circ} \mathrm{C}$. The PTV injection ramp was programmed as follows: $-80{ }^{\circ} \mathrm{C}$ for $0 \mathrm{~min}$, ramped to $300{ }^{\circ} \mathrm{C}$ at $600{ }^{\circ} \mathrm{C} \cdot \mathrm{min}^{-1}$ and held at this temperature for $1.37 \mathrm{~min}$ (total injection time of $2 \mathrm{~min}$ ). Splitless mode was used during this time. After injection, the injector was additionally programmed to decrease at a rate of $720{ }^{\circ} \mathrm{C} \cdot \mathrm{min}^{-1}$ down to $270{ }^{\circ} \mathrm{C}$ and held at this temperature for $10 \mathrm{~min}$ in split mode to condition the liner for the next injection. 
GC separation was performed on a HP-5MS (30 m x $0.25 \mathrm{~mm} \times 0.25 \mu \mathrm{m})$ column from Agilent. The carrier gas was helium, and column flow was maintained at $1.2 \mathrm{~mL} \cdot \mathrm{min}^{-1}$. The oven ramp was programmed as follows: $40{ }^{\circ} \mathrm{C}$ for $2 \mathrm{~min}$, ramped to $100{ }^{\circ} \mathrm{C}$ at $10{ }^{\circ} \mathrm{C} \cdot \mathrm{min}^{-1}$, ramped to $200{ }^{\circ} \mathrm{C}$ at 5 ${ }^{\circ} \mathrm{C} \cdot \mathrm{min}^{-1}$, ramped to $280{ }^{\circ} \mathrm{C}$ at $5^{\circ} \mathrm{C} \cdot \mathrm{min}^{-1}$ and held at this temperature for $10 \mathrm{~min}$ (total chromatographic time of $46 \mathrm{~min}$ ). The transfer line between the column and the MS was at $280{ }^{\circ} \mathrm{C}$. Ionisation was carried out through electron impact (EI). Masses were scanned from m/z 40 to 500 without solvent delay. MS source and quadrupole temperatures were $230{ }^{\circ} \mathrm{C}$ and $150{ }^{\circ} \mathrm{C}$ respectively.

\section{TD/GC/MS analysis of reference standards}

Liquid standards were injected into the instrument and analysed to obtain their MS spectra and retention times. Injection was performed by equipping a desorption tube with a special glass insert and a special transportation adapter for liquid injection, both furnished by Gerstel. Before analysis, the tube was automatically inserted into the TDU and $1 \mu \mathrm{L}$ of solution was injected into the insert. TD/GC/MS parameters were the same as written above, except for the CIS-4 cryo-focusing temperature which was set to $0{ }^{\circ} \mathrm{C}$ in order to vent solvents during desorption. Moreover, a solvent delay of 4 min and the split mode were adopted.

\section{$\underline{\text { SPME extraction of spent cartridges }}$}

Automated SPME extractions were performed as previously described in Weyermann et al. ${ }^{16}$, apart from extraction temperature which was set to $80{ }^{\circ} \mathrm{C}$ (instead of $\left.20^{\circ} \mathrm{C}\right)$. A PA-coated fibre $(85 \mu \mathrm{m}$ layer) purchased from Supelco was used. Analyses were performed on an Agilent $6890 \mathrm{~N}$ gas chromatograph equipped with a normal split/splitless injector and coupled to an Agilent 5973 inert mass selective detector. Separation and detection parameters were identical to those adopted for the TD/GC/MS method.

\section{$\underline{\text { Data treatment }}$}

If not specified otherwise, aging curves were fitted with the following equation previously derived from the diffusion theory ${ }^{27}$ :

$$
S=A+B \cdot \exp (-C \cdot \sqrt{t})
$$


where $S$ is the expected peak area mean, $t$ is the time since discharge, $A$ and $B$ are two size constants (for $\mathrm{t}=\infty, A$ represent the minimal value of the signal, while for $\mathrm{t}=0, A+B$ is its maximal value), and $C$ is a characteristic curve constant which is related to the decrease rate.

To test correlation between compounds, the Spearman's rank correlation coefficient $\left(r_{s}\right)$ was estimated for each tested type of ammunition between all the couples formed by the combination of the selected target compounds.

\section{Results and discussion}

\section{Analysis of liquid standards}

Analysis of liquid standards from 55 molecules previously identified in GSR was carried out in order to evaluate the injection and separation parameters of the TD/GC/MS method. The method allowed detecting 51 of the 55 injected compounds (Figure 1 and Table S-1). Even if a PTV injector and a cold injection technique were used, some thermo-labile molecules could not be detected. Particularly, nitroglycerin (\#52) degraded during thermo-desorption and/or in the injection port and was thus not observed in chromatograms. Lower temperatures should be adopted in order to avoid this phenomenon ${ }^{16}$. N-nitrosodiphenylamine (\#53) also degraded but was totally converted in diphenylamine ${ }^{28}$. Some compounds co-eluted. Amongst them, the co-eluting couples $\mathrm{p}$-xylene/mxylene (\#4a/\#4b) and 1,4-dicyanobenzene/1,3-dicyanobenzene (\#21a/\#21b) actually showed undifferentiable mass spectra and could not be differentiated. On the contrary, styrene/o-xylene (\#5/\#6), acetophenone/o-tolunitrile (\#11/\#12), indole/2-methylnaphthalene (\#22/\#23), and 4methylbiphenyl/1-naphthalenecarbonitrile (\#33/\#34) could be differentiated. The same was possible

for isoquinoline (\#20) which co-eluted with both 1,4-dicyanobenzene and 1,3-dicyanobenzene (\#21a/\#21b). Good chromatographic efficiency and resolutions were reached, as Figure 1 illustrates. The only exceptions were the first two eluting compounds (i.e., benzene and toluene) which had relatively large peak widths. This is due to the cold injection method, which causes the slow release of the most volatile molecules into the GC column. Substances eluting after 5 min did not present this problem.

\section{$\underline{\text { HSSE analysis of spent cartridges }}$}

Three cartridges belonging to each of the nine types of ammunition were fired and extracted at 80 ${ }^{\circ} \mathrm{C}$ by HSSE stir bars and analysed using TD/GC/MS. Generally, HSSE total ion chromatograms (TICs) were characterised by a large number of peaks. Some of them were siloxane oligomers, 
which are formed during thermo-desorption by the oxidative degradation of the polydimethylsiloxane coating ${ }^{29}$. As a representative example, Figure 2a shows the TIC of a Samson .357 Magnum cartridge. The thick coating layer also produces a slight background noise along the chromatograms. Nevertheless, given the high selectivity of the mass spectral ions belonging to siloxane compounds, the additional signals did not affect the identification of target analytes. This is well illustrated in Figure $2 \mathrm{~b}$ where the superimposed extracted ion chromatograms (EICs) belonging to 12 ions of particular interest are shown. Apart from four analytes, all target compounds were detected in the GSR of all ammunition types. Differences between ammunitions were mainly quantitative (i.e., difference in their relative peak areas). The four compounds detected in only some types of cartridges were 1-methyl-3,3-diphenylurea (4 occurrences), 2,4-dinitrodiphenylamine (3 occurrences), chrysene (8 occurrences) and benzo[a]pyrene (1 occurrence).

For comparison, Samson .357 Magnum cartridges were also extracted by a PA-coated SPME fibre. Unlike HSSE, TICs obtained by SPME did not contain any major breakdown products (Figure 2c). This is both due to the difference in coatings and to the smaller volume of phase on fibres in comparison to stir bars. Despite this advantage, significantly fewer compounds were observed in SPME chromatograms as opposed to the HSSE ones. This was evident by comparing HSSE and SPME EICs for the 12 previously discussed ions in Figure $2 \mathrm{~b}$ and $2 \mathrm{~d}$, respectively.

\section{Measurement precision}

Relative standard deviations (RSDs) of the peak areas for representative compounds were calculated in order to measure the precision of the analytical method (see details in Table S-2). Many sources of variability can affect precision during HSSE extraction of spent cartridges. Thus, measurement errors may be due to variations in the analysis, the HSSE extraction, the sample preparation, the discharge and/or the powder composition ${ }^{16}$. In order to take into account all these factors, RSDs were calculated for cartridges analysed on different days (i.e., between-day precision) and using stir bars from different batches. Concerning explosion products, RSD values ranged from 3\% to $70 \%$ in all the nine types of ammunition. This interval narrowed down to $3 \%-43 \%$ without considering acenaphthylene and pyrene, which were the least reproducible compounds. RSD values for SPME are rarely mentioned in literature, but a recent study reported $71 \%$ for naphthalene and $157 \%$ for benzonitrile in spent $9 \mathrm{~mm}$ Parabellum cartridges ${ }^{16}$. The same compounds extracted by HSSE yielded better RSD values between 5\% - 34\% and 9\% - 33\%, respectively. For gunpowder compounds, the RSD values were generally higher than for explosion products, ranging from $5 \%$ to $110 \%$. This lower reproducibility may indicate that residual gunpowder in the cartridge is very vari- 
able from shot to shot. For SPME extraction of spent cartridges, RSD values of $96 \%$ and $153 \%$ were reported for diphenylamine and 2-ethyl-1-hexanol respectively ${ }^{16}$. Using HSSE to extract the same compounds, RSD values between $7 \%-110 \%$ and $8 \%-73 \%$ were respectively obtained.

\section{GSR aging}

The evolution of the detectable target compounds as a function of time was followed using the developed HSSE method. This study was carried out during a period of $31 \mathrm{~h}$ with two different types of .45 ACP ammunition: Magtech (single-base) and Geco (double-base). Generally, the GSR chromatograms strongly evolved during the cartridges' aging but not all the target substances had the same behaviour over time. Aging rates were actually found to be dependent on the nature of the considered compound and slightly influenced by the type of cartridge.

On the one hand, the different gunpowder components seemed to remain essentially constant over time, or at least did not follow any recognizable aging trend in both types of ammunition during the studied period. Considering that these compounds were mainly trapped in unburned powder flakes, their high persistence can be ascribable to a difficulty in escaping from this matrix, which in turn leads to an important slowing-down of their loss from the cartridges. Thus, they seem of little use for dating purposes, considering also their weak reproducibility (see previous section).

On the contrary, most of the explosion products significantly diminished over time (Figure 3). Geco ammunition generally gave faster and less reproducible aging profiles compared to those obtained from Magtech for the same molecules. In fact, analytes in Geco cartridges globally levelled off $2 \mathrm{~h}$ after discharge, while aging in Magtech ammunition appeared to be more variable. In the latter case, the substances' decrease rates were found to be directly correlated with their boiling points (BPs). For example, naphthalene $\left(\mathrm{BP}=218{ }^{\circ} \mathrm{C}^{30}\right)$ diminished quickly from spent cartridges $(70 \%$ of its signal was lost in the first $2 \mathrm{~h}$ after the discharge), while acenaphthene $\left(\mathrm{BP}=279{ }^{\circ} \mathrm{C}^{30}\right)$ decreased more slowly and did not level off after $31 \mathrm{~h}$ yet (Figure 3 ). As a general representation of the relationship between the BPs and decrease rates, Figure 4 shows the plot of the estimated $C$ parameters of the compounds' aging curves versus their GC retention times in Magtech cartridges (according to equation (1), $C$ is related to the decrease rates). It can thus be noticed that the higher the retention time of the compound is, the slower its decrease.

Levelling-off of the aging curves seemed to indicate that the diffusion of GSR compounds was actually characterised by two distinct phases. In the first aging stage, the decrease was generally rapid. As a high amount of vapours was released during the discharge, the excess was probably lost rapidly because of the important gradient formed between the internal and external atmospheres. Then, 
equilibrium between compounds in the vapour phase and those adsorbed on surfaces such as walls and particles was probably established, making their decrease slower in this second phase. If we considered the aging curve of naphthalene (Figure 3a), while its decrease was very rapid and essentially levelled off $2 \mathrm{~h}$ after discharge, the residual signal was still relatively high after $31 \mathrm{~h}$. The same observation was previously reported for the escape of naphthalene and nitrocellulose decomposition products from barrels ${ }^{15}$. Because of this non-linear diffusion trend, most of the selected target substances were still detected in both cartridges $31 \mathrm{~h}$ after discharge, making the difference between GSR chromatograms at $\mathrm{t}=0 \mathrm{~h}$ and $\mathrm{t}>0 \mathrm{~h}$ essentially quantitative and not qualitative.

Reliability of aging profiles was also correlated to the compounds' BPs. Aging curves for low-BP compounds generally gave higher coefficients of determination $\left(R^{2}\right)$ after regression analysis in comparison to high-BP compounds. For example, $R^{2}$ values for benzonitrile $\left(\mathrm{BP}=191{ }^{\circ} \mathrm{C}^{30}\right.$ ) reached 0.995 and 0.741 in the two types of ammunition, while values for pyrene $\left(\mathrm{BP}=393{ }^{\circ} \mathrm{C}^{30}\right)$ were quite low: -0.012 and -0.033 (Figure 3). As a result, measurements for high-BP compounds were often not sufficiently reproducible in comparison to their decrease rates to significantly discriminate shots of different ages.

\section{$\underline{\text { Ratios between compounds as aging indicators }}$}

In order to stabilize trends and solve the problem of data variability (particularly for high-BP compounds), normalization to other compounds or internal standards is a common stratagem in analytical chemistry ${ }^{31,32}$. From a general point of view, an adequate normalization strategy would be to determine ratios between compounds for which the measured signal vary similarly. This is particularly important because it is essential that the reference and normalized compounds are submitted to the same variability-introducing factors. Internal standards added to the vial before the HSSE extraction would not be sufficient since they would account only for the variability introduced by the extraction procedure and the analytical method, and not for the heterogeneity of the powder composition and the shooting conditions (e.g., the temperature and pressure in the cartridge during the gunpowder explosion). Unfortunately, these latter factors are likely responsible for most of the variability affecting the results. In this regard, substances which are simultaneously produced during the discharge are subjected to the same variability-introducing factors and are expected to present closer mutual fluctuations. Normalizing the response of a target compound with those of another correlated substance thus seemed a promising solution.

To test the correlation between compounds, Spearman's rank correlation $\left(r_{s}\right)$ was calculated between all the couples formed by the combination of the 51 observable target analytes. Amongst the 
1327 formed couples, only 407 (about 31\%) were found to be strongly correlated (i.e., $r_{s}>0.7$ ) in at least one type of cartridge. The relatively small percentage of correlated couples is not surprising. In fact, it should be noted that not all the explosion products are simultaneously produced during the discharge, but their formation can be explained by multiple step reaction mechanisms in which larger products (e.g., pyrene and benzo[a]pyrene) are formed by the addition of radicals to smaller molecules (e.g., benzene and naphthalene) through different chemical pathways ${ }^{33,34}$. This means that similar molecules more probably come from a similar reaction pathway, resulting in high correlation. Indeed, in our research, isomers gave the best values. The correlation patterns also slightly depended on the type of ammunition. This can be explained by changes in the explosion temperature and pressure from cartridge to cartridge. However, some groups of compounds remained strongly correlated amongst the two tested types of ammunition. These are, for example, the groups formed by:

- naphthalene, 1-methylnaphthalene, 2-mehtylnaphthalene, biphenyl, 4-methylbiphenyl, fluorene and acenaphthene,

- phenanthrene, fluoranthene and pyrene

- benzonitrile, benzyl nitrile and the three tolunitrile isomers.

Ratios between signals belonging to the different couples of correlated molecules were determined in order to evaluate their usefulness for dating purposes. In many cases, the aging curves of the new indicators presented more reproducible values and slower decrease rates in comparison to those of the single molecules. A representative example is shown in Figure 5, where the aging curves of acenaphthene (Acp) and phenanthrene (Phe) are reported for the two tested types of ammunition, along with those of their ratios (Acp/Phe). For single molecules, dispersion of peak areas was relatively high at the different tested ages yielding low $R^{2}$ after regression analysis (i.e., 0.612 and 0.631 for Acp, and 0.006 and -0.005 for Phe in Magtech and Geco cartridges, respectively). On the contrary, dispersion of the ratios' values was smaller and resulted in improved $R^{2}$ values for the Acp/Phe aging curves ( 0.800 and 0.856 , respectively). In addition to this, it is also evident that the decrease rates for the Acp/Phe aging curves were slower than those of the single components. Indeed, they actually presented a quite linear trend. This slow-down effect was particularly significant for low-BP correlated molecules such as benzonitrile and o-tolunitrile. In fact, while these analytes showed a very quick decrease in their signals after the discharge and reached a steady state after a couple of hours, the aging curve of their ratio did not to seem to level off after $31 \mathrm{~h}$ of aging. 407 ratios were tested in this work and, amongst them, 154 (38\%) presented slower decrease rates than 
both their composing molecules in the Magtech ammunition, and 264 (65\%) in the Geco ammunition.

Generally, the decrease rates of the ratios obtained by inter-normalizing compounds depended on the difference between the decrease rates of the respective components. For example, ratios obtained from substances showing comparable decrease rates tended to be constant over time (i.e., they did not show any appreciable decrease), while for the compounds showing very different rates, the decrease rate of the obtained ratio was closer to that of the fastest decreasing substance. Intermediate situations were the most interesting because they allowed effectively slowing down the decrease rates and conserving a noticeable monotonic decrease. Apart from acenaphthene/phenanthrene and benzonitrile/o-tolunitrile, particularly interesting combinations were benzyl nitrile/1-naphthalenecarbonitrile, benzyl nitrile/2-naphthalenecarbonitrile, 1methylnaphthalene/phenanthrene, 2-methylnaphthalene/phenanthrene, biphenyl/phenanthrene, and acenaphthene/fluorene.

\section{$\underline{\text { Implementation in forensic caseworks }}$}

As demonstrated above, the suggested HSSE approach offers several advantages over existing extraction procedures (e.g., SPME) to analyse GSR volatile organic compounds in handgun cartridges (i.e., sensitivity and reproducibility). However, further research will be necessary in order to apply the approach in real forensic cases. Particularly, GSR aging kinetics in daily casework will be affected by the ammunition and firearm used, as well as other influence factors, such as the storage conditions. For example, Andrasko et al. ${ }^{23}$ demonstrated that GSR compounds' diffusion was influenced by the environmental temperature and found that cold weather did quenched the aging. They also showed that calibre and ammunition type were important parameters affecting the aging of the selected target compounds. Other factors such as humidity, wind speed or cartridge position were not addressed yet, but would probably affect GSR aging as well. Future works should thus consider these parameters in order to implement $\mathrm{HSSE} / \mathrm{TD} / \mathrm{GC} / \mathrm{MS}$ for dating in caseworks ${ }^{32}$.

\section{Conclusions}

A novel approach for studying the aging of gunshot residue (GSR) volatile organic compounds in handgun cartridges was developed in this work. This approach was based on the headspace sorptive extraction (HSSE) of the fired cartridges followed by thermal desorption and analysis using gas chromatography/mass spectrometry. The developed analytical method allowed, for the first time, the detection of 51 GSR compounds from fired cartridge cases. Moreover, compared to solid phase 
micro-extraction (SPME), HSSE was found to be more reproducible and effective, allowing simultaneous analysis of more compounds when applied to the same spent cartridge.

The method was applied to follow the evolution of GSR volatile organic compounds in two types of .45 ACP ammunition. Results showed that many compounds presented noticeable aging profiles and could thus be exploited for the purpose of estimating the time since discharge. Compound-tocompound ratios were tested and proved to be beneficial both in reducing the variability of the aging curves and in enlarging the time window useful for producing data in a forensic context. The obtained results are particularly promising regarding the full development of a forensic dating methodology for handgun and related cartridges. The analytical method should now be validated for practical forensic implementation, taking into account the factors influencing the aging and particular circumstances surrounding the discharge.

\section{Associated content}

Additional information as noted in the text. This material is available free of charge via the Internet at http://pubs.acs.org.

\section{Acknowledgements}

This work has been kindly supported by the Swiss National Foundation (Grant no. PP00P1_123358). The authors would like to thank Dr. Juan Manuel Garcia Gongora and Thibault Genessay from the Institut de Police Scientifique (Lausanne, Switzerland), as well as Dr. Arie Zeichner, former member of the Israeli Police (Jerusalem, Israel), for their precious advice.

\section{Bibliography}

(1) Andersson, C.; Andrasko, J. J. Forensic Sci. 1999, 44, 211-213.

(2) Bridgemon, R. R. AFTE J. 1986, 18, 49-52.

(3) Lucas, A. In Forensic chemistry and scientific criminal investigation, Lucas, A., Ed.; Edward Arnold \& Co.: London, 1935.

(4) Sokol, J. Die Bestimmung des Zeitpunktes, wann eine Waffe das letztemal beschossen und eine Partone verfeuert werde. Ph.D. thesis, University of Bern, 1939.

(5) Price, G. J. Forensic Sci. Soc. 1968, 8, 83-90.

(6) Sinha, J. K. J. Forensic Sci. 1976, 21, 171-175. 
(7) Voskertchian, G. P.; Pavilova, G. V. AFTE J. 1994, 26, 216-222.

(8) Aginsky, V. N.; Lesnikov, V.; Sorokina, G. In Proceedings of the 14th meeting of the International Association of Forensic Sciences, 1996.

(9) Romolo, F. S.; Margot, P. Forensic Sci. Int. 2001, 119, 195-211.

(10) Dalby, O.; Butler, D.; Birkett, J. W. J. Forensic Sci. 2010, 55, 924-943.

(11) Pun, K.-M.; Gallusser, A. Forensic Sci. Int. 2008, 175, 179-185.

(12) Andrasko, J. J. Forensic Sci. 1992, 37, 1030-1047.

(13) Basu, S. J. Forensic Sci. 1982, 27, 72-91.

(14) Wolten, G. M.; Nesbitt, R. S. J. Forensic Sci. 1980, 25, 533-545.

(15) Andrasko, J.; Norberg, T.; Stahling, S. J. Forensic Sci. 1998, 43, 1005-1015.

(16) Weyermann, C.; Belaud, V.; Riva, F.; Romolo, F. S. Forensic Sci. Int. 2009, 186, 29-35.

(17) Laza, D.; Nys, B.; De Kinder, J.; Kirsch-De Mesmaeker, A.; Moucheron, C. J. Forensic Sci. 2007, 52, 842-850.

(18) Mach, M. H.; Pallos, A.; Jones, P. F. J. Forensic Sci. 1978, 23, 433-455.

(19) Cropek, D. M.; Kemme, P. A.; Day, J. M.; Cochran, J. Environ. Sci. Technol. 2002, 36, 43464351.

(20) Pawliszyn, J. Solid phase microextraction: theory and practice; John Wiley \& Sons: New York, 1997.

(21) Andrasko, J.; Stahling, S. J. Forensic Sci. 2000, 45, 1250-1255.

(22) Wilson, J. D.; Tebow, J. D.; Moline, K. W. J. Forensic Sci. 2003, 48, 1298-1301.

(23) Andrasko, J.; Stahling, S. J. Forensic Sci. 1999, 44, 487-495.

(24) Andrasko, J.; Stahling, S. J. Forensic Sci. 2003, 48, 307-311.

(25) Tienpont, B.; David, F.; Bicchi, C.; Sandra, P. J. Microcolumn Sep. 2000, 12, 577-584.

(26) Baltussen, E.; Sandra, P.; David, F.; Cramers, C. J. Microcolumn Sep. 1999, 11, 737-747.

(27) Gallidabino, M.; Weyermann, C.; Romolo, F. S.; Taroni, F. Sci. Justice 2013, 53, 41-48.

(28) Jelisavac, L.; Filipovic, M. Chromatographia 2002, 55, 239-241.

(29) Stopforth, A. Stir bar sorptive extraction and gas chromatography - mass spectrometry for the analysis of biological matrices. Ph.D. thesis, University of Stellenbosch, 2007.

(30) Lide, D. R. CRC Handbook of chemistry and physics, 74th ed.; CRC Press: Boca Raton, FL, 1994.

(31) EPA. Method 8000C, rev. 3: determinative chromatographic separations, 2003.

(32) Weyermann, C.; Almog, J.; Bügler, J.; Cantu, A. A. Forensic Sci. Int. 2011, 210, 52-62.

(33) Richter, H.; Howard, J. B. Prog. Energy Combust. Sci. 2000, 26, 565-608. 
(34) Ravindra, K.; Sokhi, R.; Van Grieken, R. Atmos. Environ. 2008, 42, 2895-2921.

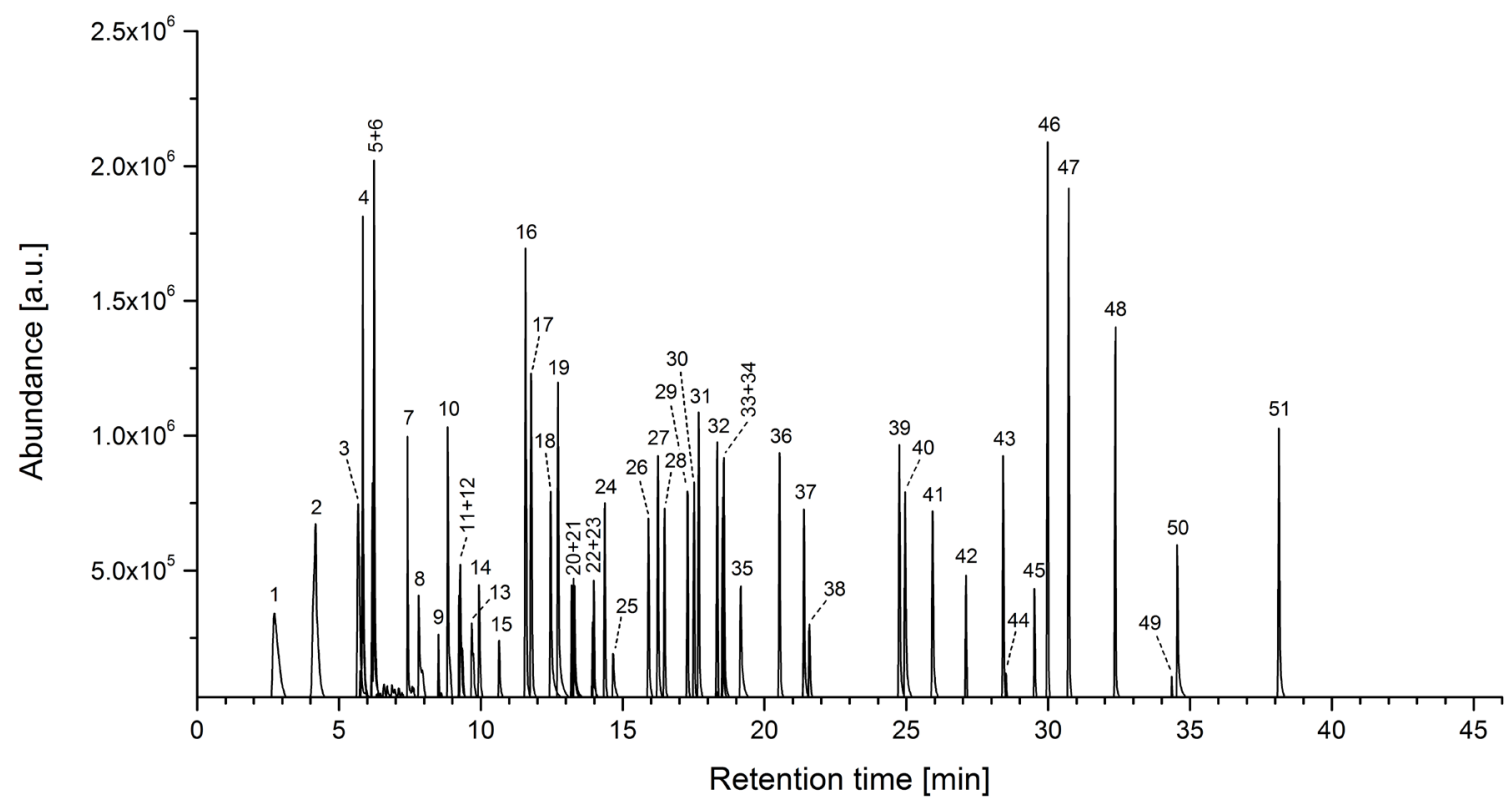

Figure 1 - Superimposed extracted ion chromatograms (EICs) of the injected standards. Correspondence between numbers and substances are explained in Table S-1. 

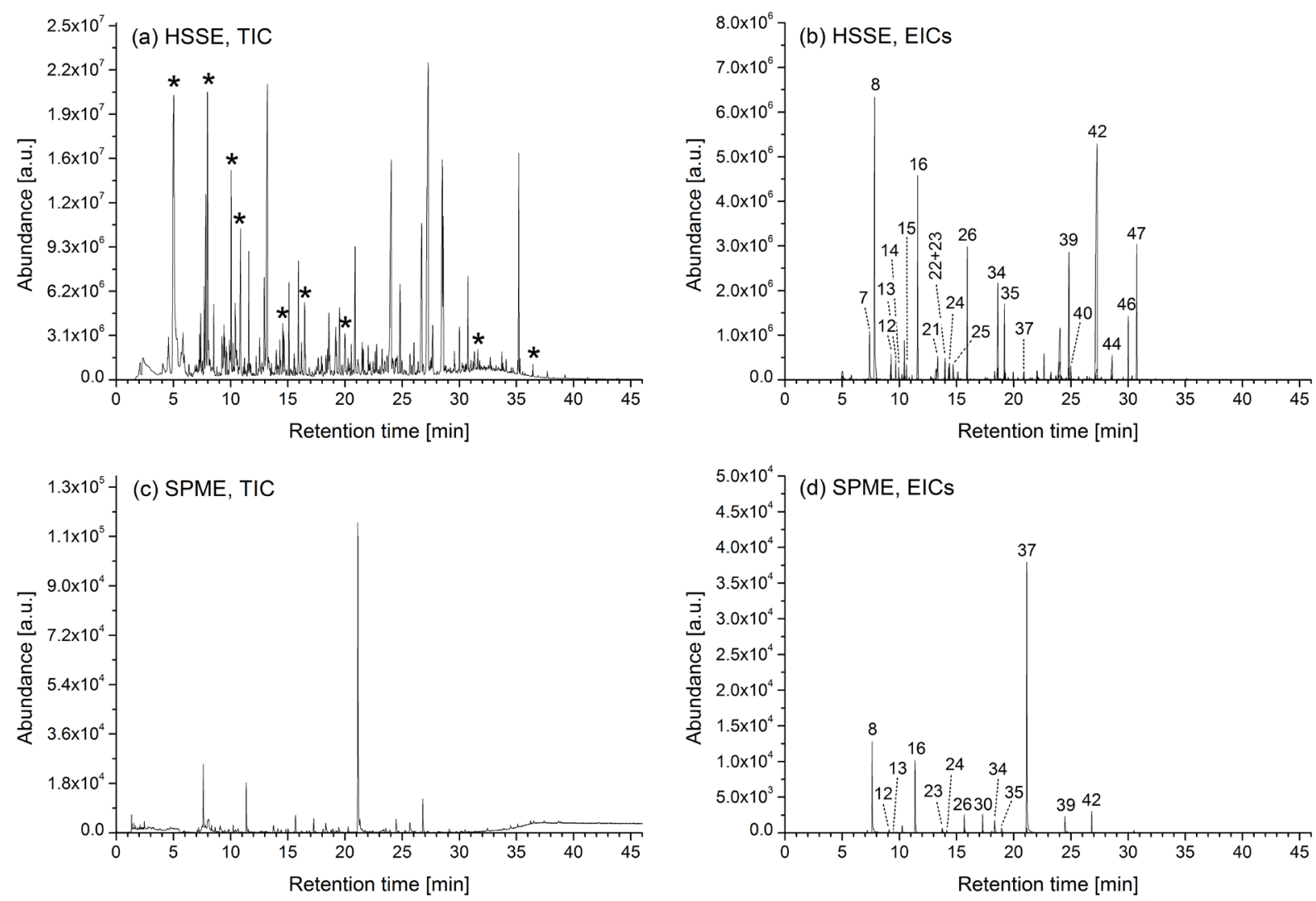

Figure 2 - Total ion chromatograms (TICs) and extracted ion chromatograms (EICs) of a fired Samson .357 Magnum cartridge extracted by HSSE (TIC: a; EICs: b) and SPME (TIC: c; EICs: d), at an extraction temperature of $80{ }^{\circ} \mathrm{C}$. EICs are given as the superimposed traces for 12 ions of particular interest. Asterisks in the HSSE TIC indicate peaks belonging to major siloxane oligomers. 

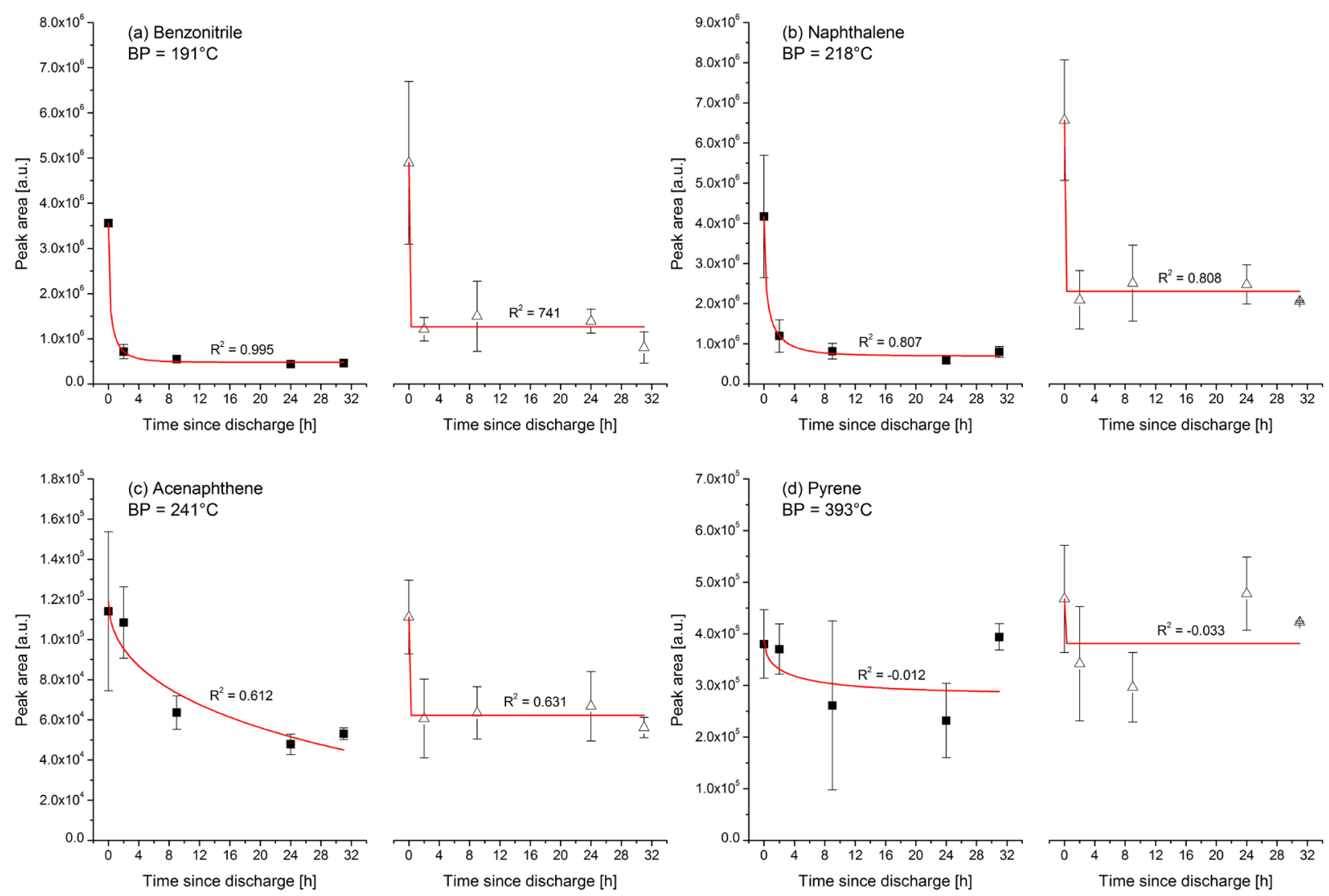

Figure 3 - Evolution of the peak areas observed by HSSE/TD/GC/MS for 4 target analytes in two types of .45 ammunition: Magtech (squares) and Geco (triangles). Measurements were fitted with Equation (1). 


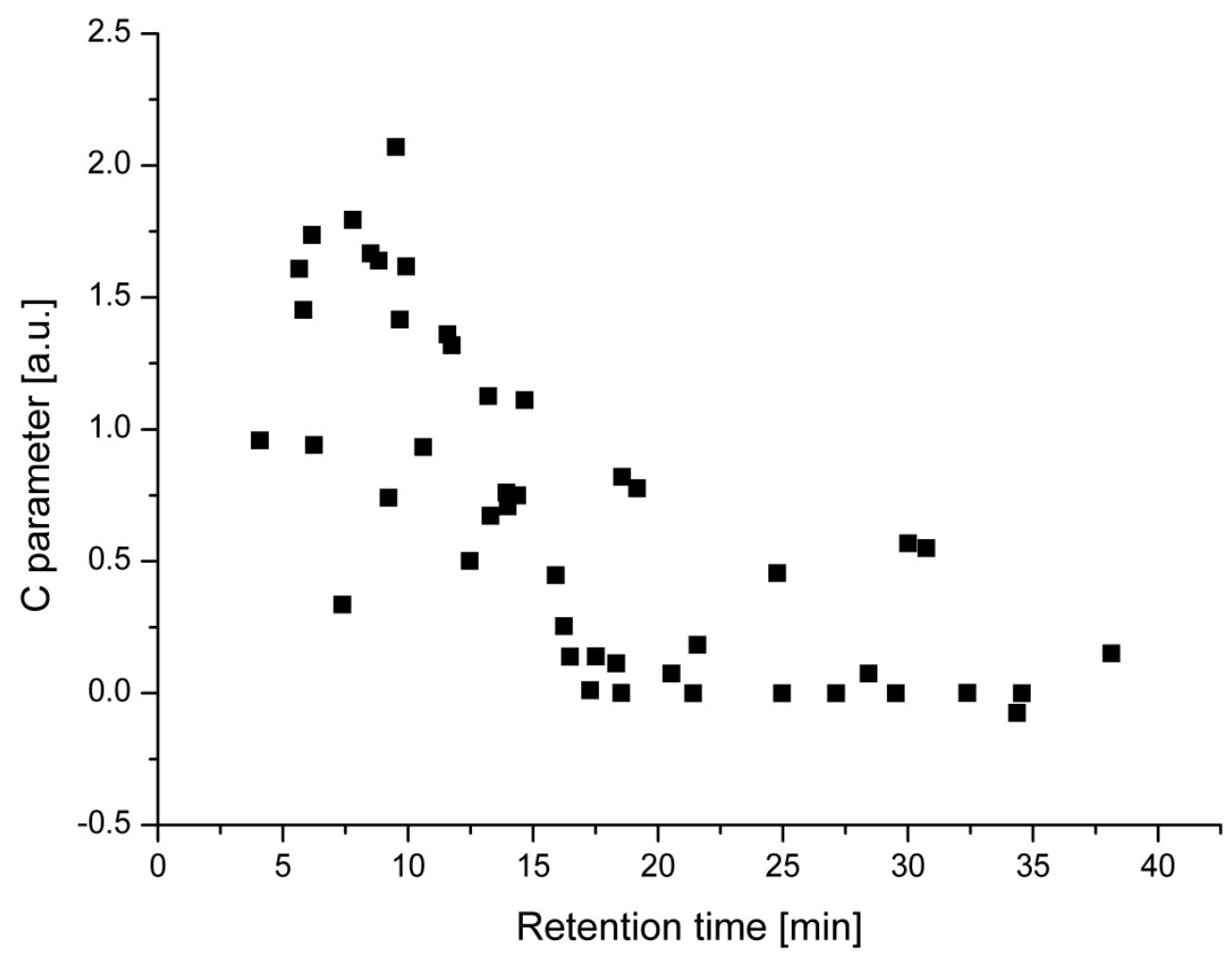

Figure 4 - Characteristic $C$ constant for the aging curves (Equation 1) of all the target analytes detected in the Magtech $.45 \mathrm{ACP}$ spent cartridges versus their respective retention time $\left(\mathrm{t}_{\mathrm{R}}\right) . C$ is related to the decrease rate. 

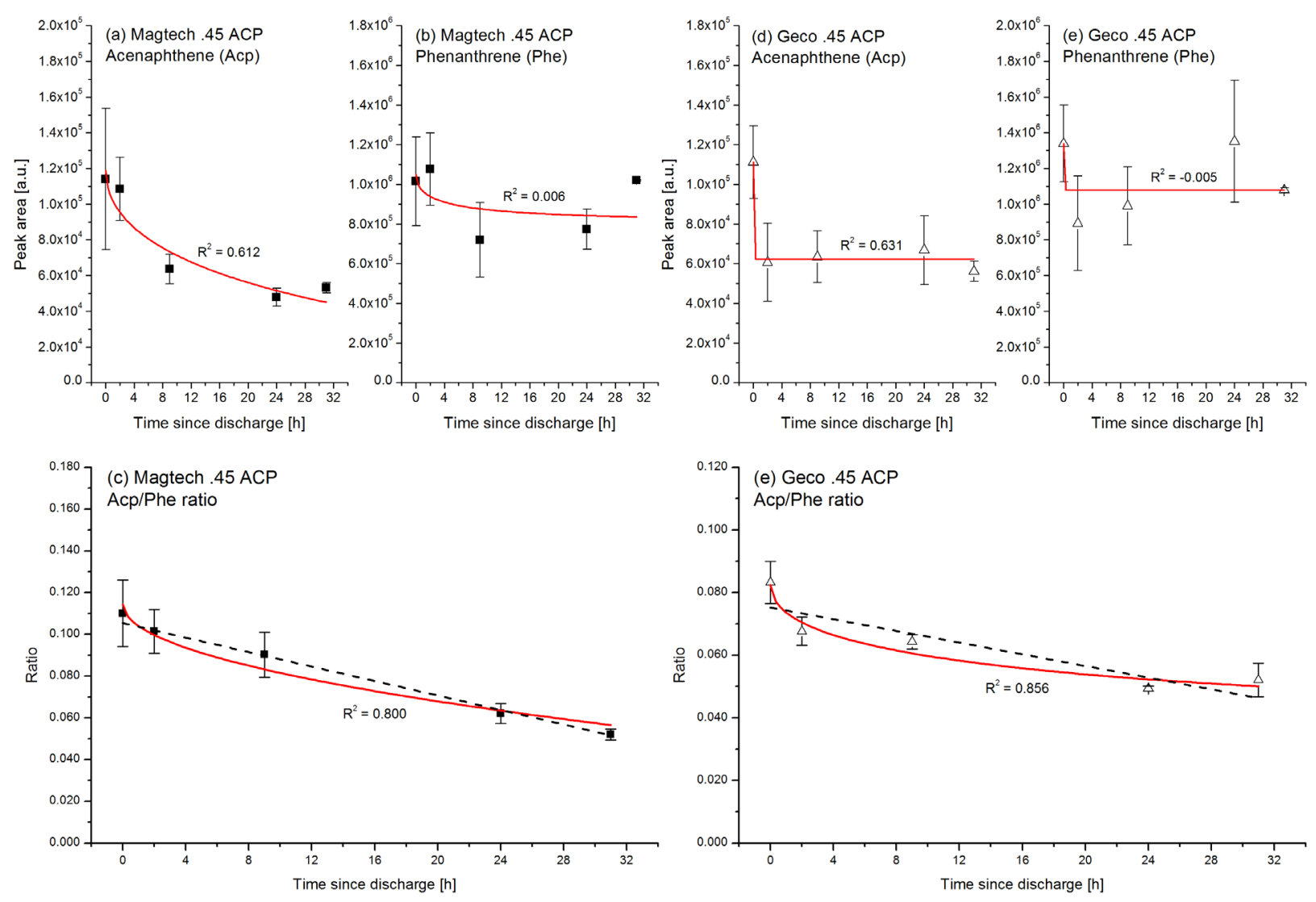

Figure 5 - Evolution over time of selected compounds and their respective ratios in two $.45 \mathrm{ACP}$ cartridges. Solid lines are the regression curves obtained by fitting the data with the non-linear regression model reported in Equation (1), while dashed lines are the curves obtained by simple linear regression. 


\begin{tabular}{|c|c|c|c|c|c|}
\hline \multirow{2}{*}{$\#$} & \multirow{2}{*}{ Substance } & \multirow{2}{*}{ Origin } & \multirow{2}{*}{ BPref } & \multicolumn{2}{|c|}{$R S D$} \\
\hline & & & & HSSE & SPME \\
\hline 7 & Benzaldehyde & $\mathrm{E}$ & $178^{\circ} \mathrm{C}$ & $4 \%-23 \%$ & \\
\hline 8 & Benzonitrile & $\mathrm{E}$ & $191{ }^{\circ} \mathrm{C}$ & $9 \%-33 \%$ & $157 \%$ \\
\hline 13 & m-Tolunitrile & $\mathrm{E}$ & $213^{\circ} \mathrm{C}$ & $4 \%-35 \%$ & \\
\hline 16 & Naphthalene & $\mathrm{E}$ & $218^{\circ} \mathrm{C}$ & $5 \%-34 \%$ & $71 \%$ \\
\hline 23 & 2-Methylnaphthalene & $\mathrm{E}$ & $241{ }^{\circ} \mathrm{C}$ & $3 \%-31 \%$ & \\
\hline 26 & Biphenyl & E & $256{ }^{\circ} \mathrm{C}$ & $5 \%-43 \%$ & \\
\hline 30 & Acenaphthylene & $\mathrm{E}$ & $270{ }^{\circ} \mathrm{C}$ & $5 \%-70 \%$ & \\
\hline 34 & 1-Naphthalenecarbonitrile & $\mathrm{E}$ & $299^{\circ} \mathrm{C}$ & $7 \%-28 \%$ & \\
\hline 39 & Phenanthrene & $\mathrm{E}$ & $340^{\circ} \mathrm{C}$ & $4 \%-32 \%$ & \\
\hline 47 & Pyrene & E & $393{ }^{\circ} \mathrm{C}$ & $11 \%-55 \%$ & \\
\hline 9 & 2-Ethyl-1-hexanol & G & $185^{\circ} \mathrm{C}$ & $8 \%-73 \%$ & $153 \%$ \\
\hline 37 & Diphenylamine & G & $302{ }^{\circ} \mathrm{C}$ & $7 \%-110 \%$ & $96 \%$ \\
\hline 42 & Ethylcentralite & G & $?$ & $9 \%-33 \%$ & \\
\hline 43 & Dibutylphthalate & G & $340^{\circ} \mathrm{C}$ & $12 \%-74 \%$ & \\
\hline 44 & 2-Nitrodiphenylamine & G & $?$ & $5 \%-103 \%$ & \\
\hline
\end{tabular}

Table 1 - Ranges for the relative standard deviations (RSDs) of peak areas of selected compounds detected in nine types of handgun cartridges using HSSE extraction Values represent the between-day precision $(\mathrm{n}=3)$ and were compared to those reported in the literature for SPME extraction. "E" indicates explosion products and "G" gunpowder components. 